\title{
Trade in pegasid fishes (sea moths), primarily for traditional Chinese medicine
}

\author{
Amanda C. J. Vincent
}

Pegasid fishes (sea moths) have only entered the arsenal of traditional Chinese medicine within the past few decades, but are now used in southern China and Hong Kong to treat respiratory ailments and cancers. Brief trade surveys suggest that millions of individuals of two pegasid species are used each year, and that they cost relatively little compared with other ingredients. Most pegasids are apparently a bycatch of trawl fishing, which has recently intensified near China. Trade and use of these fishes is expanding - they have been sought in the Philippines, Indonesia and Vietnam - and should be monitored, particularly because the biology of pegasids makes these fishes vulnerable to exploitation.

\section{Introduction}

Traditional Chinese Medicine (TCM) depends heavily on animal and plant products, with ever more resources consumed by the People's Republic of China (PRC) in response to its great economic growth since the mid1980s. This dependency poses well-publicized threats to rhinoceroses, tigers and bears but we still know little about the conservation status of most other species embraced by the TCM pharmacopaeia. Fishes are particularly neglected, even though a preliminary and incomplete list cites use of 58 species (Tang, 1987). Recent work points out that growing TCM demand threatens seahorses and pipefishes (Vincent, 1995, 1996). I here discuss the TCM trade in fishes of the marine family Pegasidae, and comment on the conservation concerns raised thereby. This trade has not previously been documented and the fishes themselves remain virtually unstudied.

\section{Study species}

Pegasids (sea moths, sea birds, sea swallows or sea sparrows) are small marine fishes, seldom exceeding $100 \mathrm{~mm}$ long (Figures 1 and 2). They go by Chinese names of hai'e, hai yan or hai ma que (pinyin romanization as used in the
PRC). Pegasus volitans (Cuvier) is also referred to as fei hai'e. The pegasids' highly distinctive morphology includes a body enclosed in a rigid carapace formed of fused plates, ventral flattening, huge pectoral fins (hence their name reminiscent of winged horses), rolled pelvic fins and a small protruding mouth. This latter feature is one reason why pegasids are classified in a sister group (Pegasoidea) to the seahorses and pipefishes (Syngnathoidea; Pietsch, 1978).

Pegasids inhabit temperate and tropical seas of the Indo-Pacific region, from South Africa to Hawaii. The family is currently thought to consist of five species in two genera, Pegasus and Eurypegasus (Palsson and Pietsch, 1989; see Figures 3 and 4 for occurrence). Other generic names, now discredited, include Acanthopegasus and Parapegasus. Pegasids live on open sand or mud substrate in calm areas, such as bays and estuaries, and prefer coarser sediments or the presence of seagrass (Kuiter, 1985). Although pegasids have been collected to maximum depths of at least $291 \mathrm{~m}$, they are more commonly found in relatively shallow coastal waters in as little as $1 \mathrm{~m}$ of water (although this varies by species; Palsson and Pietsch, 1989). Larvae and juveniles to $30 \mathrm{~mm}$ may be found planktonically (Palsson and Pietsch, 1989). Pegasids are usually diurnal but juveniles and adults can be attracted by 


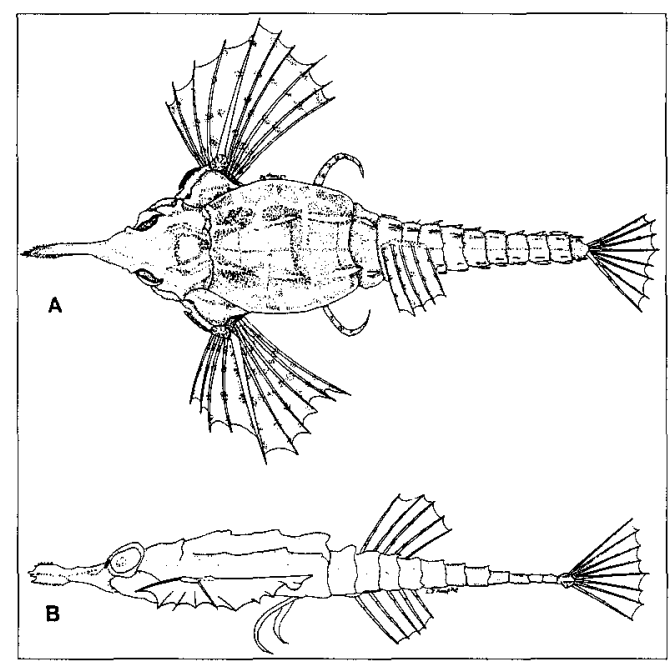

Figure 1. P. laternarius SL $60.9 \mathrm{~mm}$ (A) Dorsal view (B) Lateral view. Drawn by Lana J. Koepke. From Palsson and Pietsch (1989), reproduced with the permission of Wayne A. Palsson.

lights at night, and rise to the surface (Kuiter, 1985).

The few brief studies of pegasid biology indicate that the same pairs of one male and one female mate repeatedly - perhaps because of their low density and low mobility - but show neither parental care nor site fidelity (Pegasus lancifer; Kuiter, 1985; Eurypegasus draconis; Herold and Clark, 1993). Pegasids walk or crawl along the bottom on their pelvic fins, only occasionally using their large pectorals to 'fly'. Many $P$. lancifer congregate in estuarine shallows on a seasonal basis (Kuiter, 1985). Seasonal migrations are suggested by the fact

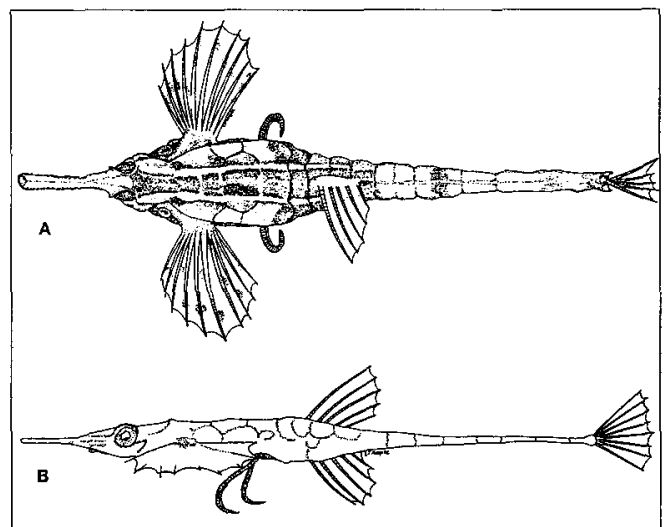

Figure 2. P. volitans SL $89.4 \mathrm{~mm}$ (A) Dorsal view (B) Lateral view. Drawn by Lana J. Koepke. From Palsson and Pietsch (1989), reproduced with the permission of Wayne A. Palsson.

that they are trawled with prawns only during certain periods of the year (Kuiter, 1985).

Sexes of $E$. draconis do not differ in total length or colour but the female has a larger carapace volume while the male has a significantly longer tail and rostrum (Herold and Clark, 1993). P. lancifer's colours are usually beige/brown/green but both sexes are highly cryptic, capable of rapid colour change to match the substrate (Kuiter, 1985). In both species, males' snouts are more slender and proportionally longer than those of females. Pegasids shed their skin in one complete piece every 1-5 days, presumably to rid themselves of accumulated epibiotic growths of algae, hydroids and other organisms (Kuiter, 1985; Herold and Clark, 1993). Strict carnivores,

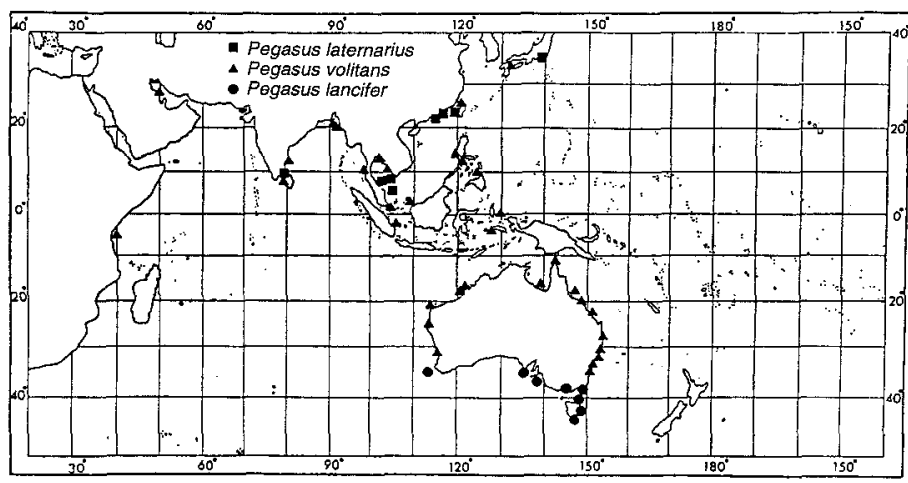

Figure 3. Occurrence map of the genus Pegasus in the Indo-Pacific, based on the origins of specimens available for inspection by Palsson and Pietsch (1989). No trade is yet known in $P$. lancifer. Drawn by Lana J. Koepke and reproduced with the permission of Wayne A. Palsson.

(C) $1997 \mathrm{FFI}$, Oryx, 31 (3), 199-208 
Figure 4. Occurrence map of the genus Eurypegasus in the IndoPacific, based on the origins of specimens available for inspection by Palsson and Pietsch (1989). No trade is yet known in this genus. Drawn by Lana J. Koepke and reproduced with the permission of Wayne A. Palsson.

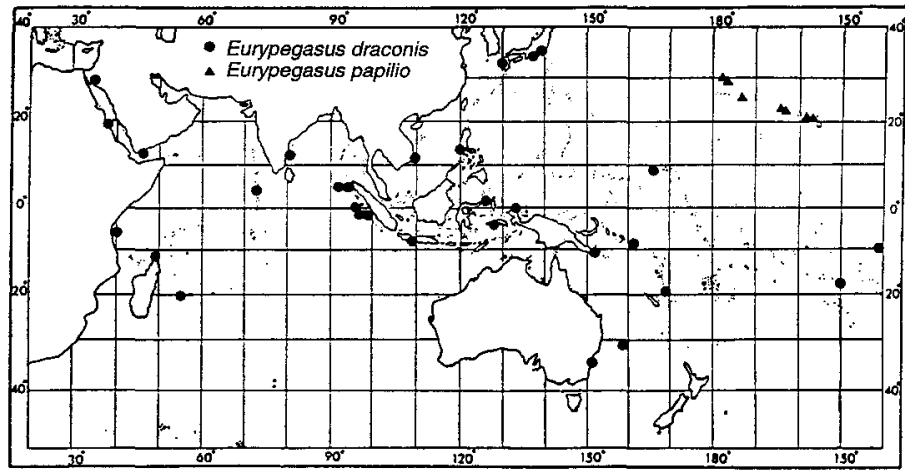

they feed by sucking small epifaunal and interstitial invertebrates from the sediment/ water interface (Herold and Clark, 1993). They have been known to fall prey to larger pelagic fish such as tuna (Palsson and Pietsch, 1989) and to birds such as penguins (Kuiter, 1985).

One of the species noted for sale for TCM, Pegasus laternarius, occurs from Indian and Western Pacific Oceans, and has been trawled up from mud bottoms at depths of 27 to $91 \mathrm{~m}$, with most found at about $50 \mathrm{~m}$ (Palsson and Pietsch, 1989). Larvae are planktonic.

The second species noted for sale in TCM, Pegasus volitans, occurs in the Indian and Western Pacific Oceans, at depths of 1 to $73 \mathrm{~m}$, with most between 9 and $27 \mathrm{~m}$ (Palsson and Pietsch, 1989). It is brought up from muddy and sandy bottoms by seine-, trawl-, dredgeand shrimp-nets. One report claims that captured $P$. volitans emit a foul smell (Babu, 1966). Palsson and Pietsch (1979) dismiss two recorded catches of $P$. volitans off North America as being releases from marine aquaria.

\section{Trade surveys}

Most information in this paper was collected through field work in China and Hong Kong during May 1993 and April and May 1995. Interviews and surveys focused on seahorses, only secondarily considering the pegasid trade. The approach was to seek out the director of the major government TCM products importer(s) in the larger coastal cities of southern and south-eastern China (Beihai,
Haikou, Zhejiang, Guangzhou, Shantou, Xiamen and Fuzhou; Figure 5). Discussions lasted from 30 minutes to several hours, depending on willingness to talk to us. All interviews were in Mandarin or Cantonese, through a Hong Kong Chinese biologist, with notes made during the interview. We also visited TCM retail outlets and market stalls in each of these cities, and in Quanzhou; these were discovered haphazardly by wandering the streets and/or through talking with local people. The total number of retail outlets visited or people formally interviewed in Hong Kong and the PRC during these two trips was 87 , not including brief discussions with TCM consumers and casual meetings.

The Philippines' information comes from conversations with fishers, found by asking a wide range of people for advice as to who might know about pegasids.

\section{Sales}

Pegasids are sold whole and dried. Their sales currently appear to be restricted to Hong Kong and the southern PRC provinces of Guangxi, Guangdong and Hainan (Figure 5). According to TCM merchants interviewed, there is no tradition of local use in Fujian, the next coastal province north. Nor are pegasids commonly used in Taiwan or other parts of Asia. For example, TCM retailers in Surabaya, Indonesia (which has a large ethnic Chinese community), did not know this fish.

At least two pegasid species are sold in southern China: P. laternarius (Figure 1) and 

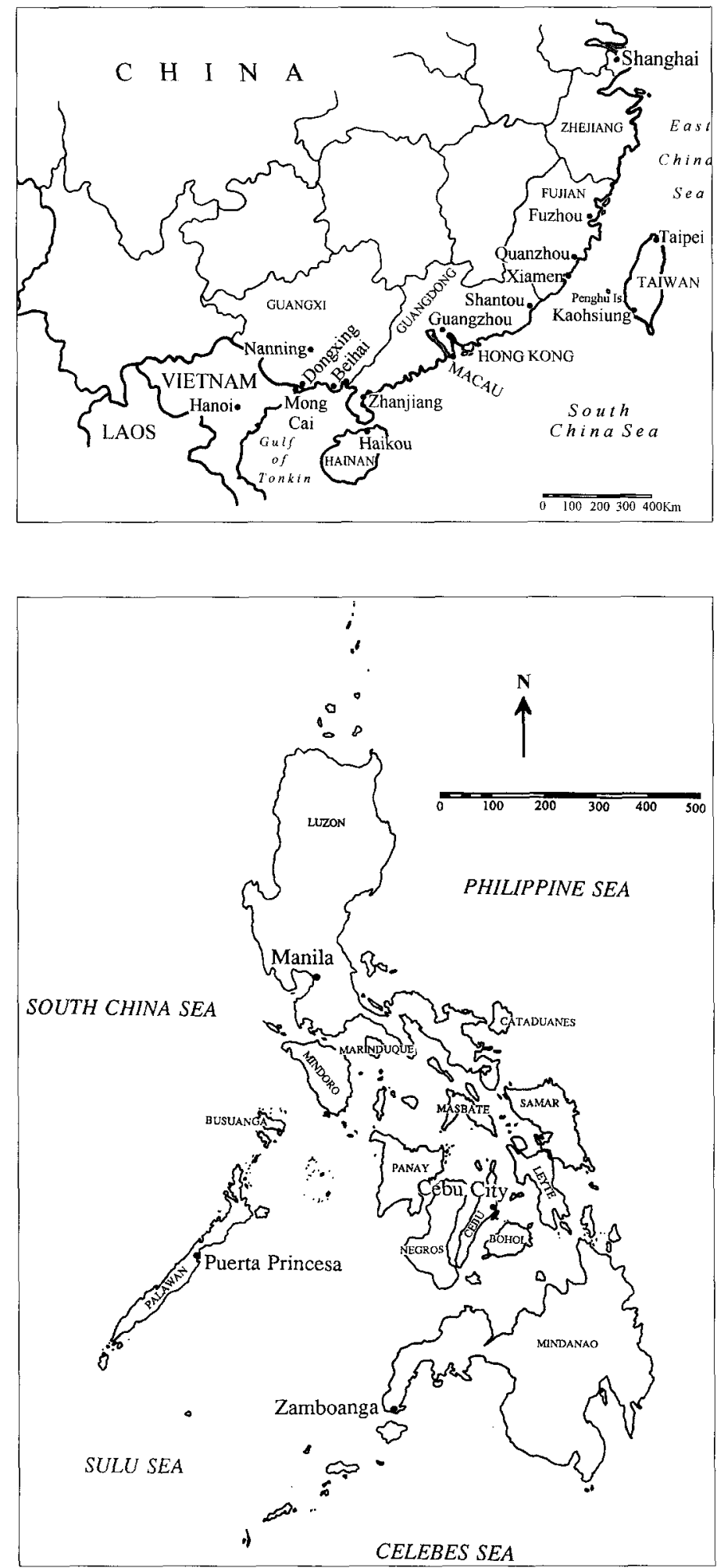

Figure 5. Map of southern China, showing places where pegasids are traded, as indicated in text.
Figure 6. Map of the Philippines, including places where pegasids are traded, as indicated in text.

(C) $1997 \mathrm{FFI}$, Oryx, 31 (3), 199-208 
P. volitans (Figure 2). Both are sold in bulk in Qingping market, Guangzhou. On Hong Kong island (Western and Causeway Bay), four of seven shops visited in May 1995 stocked pegasids, all $P$. laternarius. In an apparent dimorphism, snouts can be long or short in either species; of a collection of $29 P$. laternarius, 16 had long snouts, 11 had short snouts and two had broken snouts, that therefore appeared short.

Retail outlets commonly keep most pegasids in the refrigerator rather than on public display, but displays of about 200 pegasids were noted in some Hong Kong pharmacies during this study. Apparently pegasids are kept refrigerated because their rigid and closed carapace makes it difficult to dry them completely, so they continue to smell rather fishy.

Weights can vary considerably. A group of dried $P$. laternarius that one Hong Kong shop poured out of a bag without exercising choice weighed a mean of $1.8 \mathrm{~g}$ each $(n=20)$. A sample of dried pegasids that I manually selected (although not with any conscious bias) from three other shops weighed a mean of $2.5 \mathrm{~g}$ each $(n=8)$. The longest and widest $P$. laternarius noticed during the surveys (in Qingping market, Guangzhou, PRC) had a dry weight of $6.4 \mathrm{~g}$. A sample of dried $P$. volitans for sale in China weighed a mean of $0.9 \mathrm{~g}$ each $(n=16)$.

Dried specimens of $P$. laternarius have reportedly been collected and kept as curios in Chinese insect boxes (Günther, 1870 in Palsson and Pietsch, 1989).

\section{Medicinal use}

Pegasids are not mentioned in any of the classical TCM pharmacopoeia nor in the Encyclopaedia of Chinese Materia Medica (Zhongyao Dacidian; Jiangsu New Medical College, 1977). They are, however, cited in some of the most recent works on medicinal animals (Zhongguo Yaoyong Dongwu Zhi Medicinal Fauna in China Committee, 1983; Wan and $\mathrm{Wu}, 1993$ ).

Use of pegasids varies among regions but they appear to be primarily applied to respir- atory ailments (Zhongguo Yaoyong Dongwu Zhi Medicinal Fauna in China Committee, 1983). Pegasids are also reputed to help with lymph node and thyroid disorders, and to remove phlegm and abnormal secretions. Rumours credit pegasids with curing throat and breast cancer; one TCM importer reported that researchers in Nanning, Guangxi region (Figure 5) are currently investigating the latter role. Preliminary results suggest that pegasid extract may have significant effects on adenosine and $\mathrm{LTD}_{4}$ receptors (P. But, pers. comm.)

Pegasids are commonly consumed as tonic foods, rather than prescription medicines. A pocket manual for the general public claims that pegasids function to reduce coughing and mucous production (associated with children's bronchial infections in particular), and to improve sexual function and kidney function ( $\mathrm{Li}$ and $\mathrm{Lin}, 1992)$. They are also considered helpful in curing goitres and diarrhoea following measles. For most treatments, the patient buys a dried pegasid, boils it with other ingredients and then drinks the liquid. For example, the cure for goitre requires the patient to mix seven to eight dried pegasids with pork to make a soup. The liquid and the constituent ingredients are ingested once daily for 3-4 days ( $\mathrm{Li}$ and $\mathrm{Lin}, 1992$ ). Some Hong Kong residents boil seahorses with salt pork and sweet olives to cure sore throats (F. Wong, pers. comm.).

Most uses for pegasids (with the exception of cancer treatments) are the same as those for seahorses, and the former are reportedly increasingly employed where the latter would have been preferred (but are unavailable or too expensive). In addition, pegasids (hai que) are blended with seahorses (hai ma), pipefishes (hai long) and sea snakes (hai shie) in a folk medley called 'Sea Treasure' (hai bao). This is claimed to act as a general tonic and aphrodisiac, increasing blood circulation, reducing wind, and cooling the body.

\section{Volumes}

Neither China nor Hong Kong publishes statistics on trade in pegasids, but field surveys 
and interviews indicate that millions of pegasids are sold each year. Examples of the survey findings are given below.

1 Qingping market in Guangzhou, PRC, is well known for the volume and variety of animal products sold, with two species of pegasid among them. As with other goods, pegasids are sold in stalls clustered together rather than evenly distributed throughout the market. Four stalls in one quarter of the medicinal products section displayed three bags of dried $P$. laternarius, each with a volume of about $15 \mathrm{~L}$. Given that 20 dried P. laternarius fill a volume of approximately $360 \mathrm{~mL}$, each bag probably held an estimated 860 pegasids. Stalls also displayed two 15-L bags of dried $P$. volitans, each estimated to contain about 2400 individual pegasids ( 20 dried $P$. volitans fill a volume of approximately $125 \mathrm{~mL}$ ). This market may thus have been displaying about 2500 $P$. laternarius and 4800 P. volitans. All pegasids were said to have been caught in the Hainan area.

2 A sales clerk in a Guangzhou, PRC retail shop reported selling about 25 pegasids monthly or 300 annually. Given that there are approximately 1000 retail outlets for TCM in
Guangzhou (see Vincent, 1996), total local sales might amount to about 300,000 pegasids annually.

3 A man with a senior rank in a large TCM business in Guangzhou, PRC, reported selling 'twice as many pegasids as seahorses by weight'. His wholesale company sells perhaps $600 \mathrm{~kg}$ of seahorses annually (Vincent, 1996) so might sell about $1200 \mathrm{~kg}$ of pegasids (666,000 individuals if the estimate of $1.8 \mathrm{~g}$ is accurate) each year in the Guangzhou area. This estimate is twice as high as that of the shop owner questioned (see above) but could be more representative because wholesalers supply a wide range of retail outlets.

4 One TCM merchant in Hong Kong, with many years experience, stated that he sold about 200 catty $(120 \mathrm{~kg})$ of $P$. laternarius annually from his shop (retail and wholesale). If the mean weight were about $1.8 \mathrm{~g}$ (see above), then his total sales would be in the order of 67,000 pegasids annually. He estimates that importers and distributors sell in 1 month what he sells in 1 year $(1440 \mathrm{~kg})$ and that there are approximately 10 large importers in Hong Kong, for a possible $14,400 \mathrm{~kg}$ (8 million pegasids). Even if this figure is a severe

Table 1. Sample prices for Pegasus laternarius and P. volitans in Hong Kong and the PRC in 1993 and 1995

\begin{tabular}{|c|c|c|c|c|}
\hline \multirow[b]{3}{*}{ Outlet } & \multicolumn{4}{|c|}{ Prices per $\mathrm{kg}$ ( $\$ \mathrm{HK}, \mathrm{RMB}$ and $\$ \mathrm{US}$ equivalents) } \\
\hline & \multicolumn{2}{|c|}{ P. laternarius } & \multicolumn{2}{|l|}{ P. volitans } \\
\hline & May 1993 & May 1995 & May 1993 & May 1995 \\
\hline $\begin{array}{l}\text { Hong Kong } \\
\text { (private, retail outlet) }\end{array}$ & $\begin{array}{l}\text { \$HK570-1028 } \\
\text { (\$US76-137) }\end{array}$ & $\begin{array}{l}\$ H K 400-800 \\
\text { (\$US52-104) } \\
\text { Tourist price, } \$ \text { US166 }\end{array}$ & & \\
\hline $\begin{array}{l}\text { Guangzhou, PRC } \\
\text { (government, retail outlet) }\end{array}$ & $\begin{array}{l}\text { RMB308 } \\
\text { (\$US54) }\end{array}$ & $\begin{array}{l}\text { RMB400 } \\
\text { (\$US48) }\end{array}$ & & \\
\hline $\begin{array}{l}\text { Guangzhou, PRC } \\
\text { (private, market stall) }\end{array}$ & & $\begin{array}{l}\text { RMB600-747 } \\
(\$ U S 72-90)\end{array}$ & & $\begin{array}{l}\text { RMB2274 } \\
\text { (\$US274) } \\
\text { (= tourist price?) }\end{array}$ \\
\hline $\begin{array}{l}\text { Beihai, PRC } \\
\text { (private, market stall) }\end{array}$ & & & & $\begin{array}{l}\text { RMB350 } \\
\text { (\$US42) }\end{array}$ \\
\hline
\end{tabular}

Currency exchange for the PRC is at \$US = RMB5.7 in 1993 and \$US = RMB8.3 in 1995.

Inflation has run at over 10 per cent in the PRC during this period (South China Morning Post-Business

Briefing, 15 January 1996). 
overestimate, the numbers are clearly substantial. Sales are seasonal, partly reflecting the occurrence of ailments that pegasids reputedly cure.

\section{Prices}

Pegasids were offered for sale at about the same price (\$US equivalent) in Hong Kong and the PRC (Table 1). Hong Kong retail prices for $P$. laternarius appeared to drop somewhat between May 1993 (\$US76-137 per $\mathrm{kg}$ ) and May 1995 (\$US52-104 per kg), but shops varied greatly in their prices (Table 1).

Within the PRC in May 1995, pegasids were offered for sale at lower prices in government outlets than in private retailers (Table 1). Based on the estimated weights in small Hong Kong samples (see above), each kilogramme of $P$. laternarius would consist of perhaps 555 individuals while each $\mathrm{kg}$ of $P$. volitans would include about 1110 pegasids. In \$US equivalents, prices for $P$. laternarius at the retail outlet of the government-owned Guangzhou drug import company were roughly the same in May 1993 (\$US54 per kg) and April 1995 (\$US48 per $\mathrm{kg}$ ). During this period, prices in local currency rose about 30 per cent between May 1993 (RMB308 per kg) and April 1995 (RMB400 per $\mathrm{kg}$ ), but this approximately equalled the rate of inflation. By comparison, prices for mixed brown seahorses increased 55 per cent (from RMB2000 to 3100 per $\mathrm{kg}$ ), and large Solegnathus hardwickii pipefishes (commonly known as seadragons) increased 52 per cent (from RMB3771 to 5740 per $\mathrm{kg}$ ) in the same shop over the same time period. A senior official in the government Chinese trade in TCM ingredients recounted that $P$. laternarius cost only RMB0.66-1.00 per $\mathrm{kg} 30$ years ago, suggesting that absolute prices might have increased 400-600 per cent over 30 years, before adjustment for inflation.

\section{Catching pegasids}

No target fishery for pegasids is known from the PRC. Trawlers seeking food fishes in the South China Sea catch pegasids incidentally (Luo Ji-Zhang, pers. comm.) and then sell

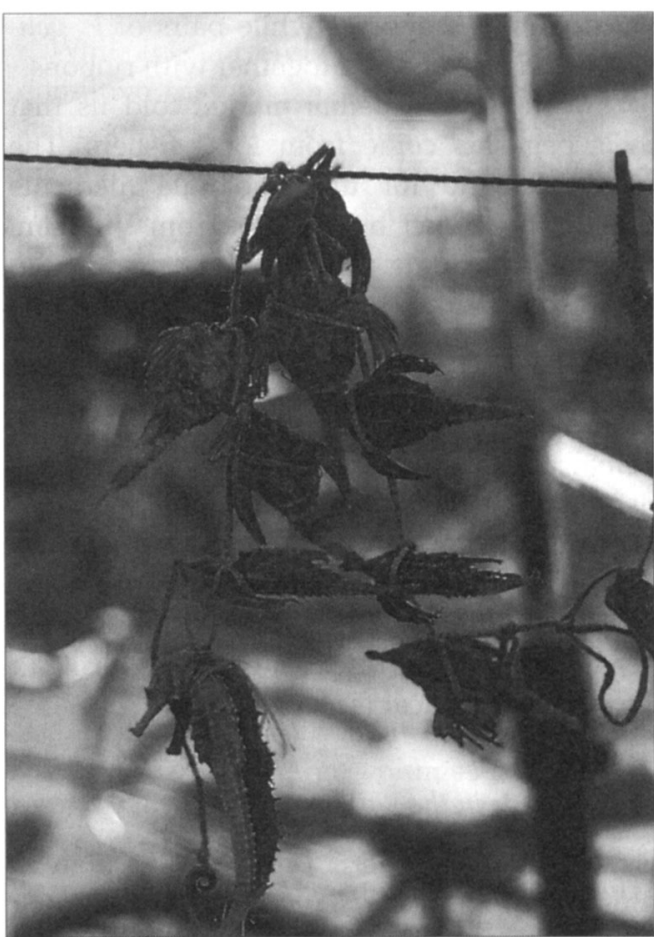

Figure 7. Dried pegasids and a pair of dried seahorses hanging for sale in Beihai market (A. Vincent).

them to buyers of dried marine products. From interviews with traders, it appears that most pegasids currently on the market in southern China and Hong Kong are probably caught in the Gulf of Tonkin (Bei Bu Wan; between Hainan, Guangxi and Vietnam; Figure 5), although a TCM importer reported that some pegasids for sale in Guangzhou may come from other areas in South East Asia.

The Gulf of Tonkin is a large sea with a mean depth of only about $40 \mathrm{~m}$; a senior fisheries official in Guangxi reported that most trawling focuses on the shallower central area ( $20 \mathrm{~m}$ deep), where there is much Sargassum algae (Luo Ji-Zhang, pers. comm.). Beihai is the leading Guangxi port on the Gulf of Tonkin, and hundreds of dried pegasids are displayed in the Beihai dried fish market (e.g. Figure 7). Stalls with pegasids also sold seahorses, pipefishes (seadragons), and sea snakes. $P$. laternarius hung singly from strings 
with pairs of seahorses while pairs of $P$. volitans lay in baskets, tied together with ribbons.

Stall holders in Beihai market told us that their pegasids come from local fishers. The larger demand for the wholesale medicine trade may be met by imports from Vietnam, probably arriving through Dongxing in Guangxi province (Luo Ji-Zhang, pers. comm.; Figure 5).

Despite the large market displays of pegasids, the government medicine agency in Beihai claimed not to be interested in these fishes stating that, 'While the demand is certainly there, the trade volume is low because they are not much prescribed by doctors'. However, they said they will start stocking pegasids if current research confirms a role in curing breast cancer (see above).

\section{Pegasid trade in the Philippines}

Fishers in the western province of Palawan (Busuanga) know P. laternarius well, and catch them in trawls on sandy bottoms at 30-40 m deep. Pegasids are also part of trawl bycatches - the target is food fishes - in the central provinces of Leyte and Bohol, and the southern province of Mindanao (Zamboanga). They are reported as appearing either in water of less than $5 \mathrm{~m}$ or in $30-60 \mathrm{~m}$ depth, over sand or mud bottoms. Ongoing research in the Philippines has not found support for the statement that $P$. volitans is often found in the country's fish markets (cf. Palsson and Pietsch, 1989) but some of the trawl bycatch is now being sold to dealers who supply TCM needs.

In 1995, Chinese marine exporters in Cebu specifically asked fishers off Bohol to deliver pegasids, for the first time. But fishers caught mostly $P$. volitans, which is currently of relatively low value in TCM. Prices were not high enough to cover the fishers' costs, especially given the small volumes they obtained. The offer to buy pegasids was rescinded but could forseeably be restored as prices rise. A target fishery could also develop if another (larger) locally available species, E. draconis, were sought for TCM.

A small number of pegasids are traded as aquarium fishes. Aquarium fish gatherers in the northern island of Luzon (Batangas and Zambales; Figure 6) report occasionally seeing pegasids (apparently $P$. volitans) on sandy or muddy bottoms at $17-30 \mathrm{~m}$, sometimes associated with soft corals. These divers seldom bother to collect the pegasids because they are difficult to keep and are only worth about \$USO.28 each.

International sales of live pegasids appear to be quite low. The largest marine aquarium fish importer in Britain recorded imports of only about $20 \mathrm{P}$. volitans (they called it Parapegasus natans) in 1996, from the Philippines. They also imported two E. draconis (they called it $P$. volitans) in 1995; these came from Sri Lanka but the same species is on offer from the Philippines.

\section{Discussion}

A lack of data on population sizes, geographic ranges or actual trade volumes makes it impossible to assess the impact of the demand for pegasids. We can, however, guess that their biology (Kuiter, 1985; Palsson and Pietsch, 1989) will make pegasids susceptible to fishing pressure because of the reasons listed below.

1 The only quantitative study of pegasid biology found that $E$. draconis lives at very low densities, with just one pair per 325-477 sq m of suitable habitat.

2 Pegasids are slow and live in open habitats, making them easy to catch with a handnet.

3 Low levels of activity imply slow recolonization of depleted areas by adults; they spend most of the day crawling over the sea bottom and then become inactive at night.

4 Their mating pattern restricts reproductive rate. $E$. draconis and $P$. lancifer, at least, are thought to be monogamous, with the same pairs mating repeatedly. Single animals apparently take a long time to find a partner, which is expected if they are pair faithful and live at low densities. Thus disrupting pairs could delay breeding.

5 Although fecundity may be relatively high some pairs can spawn several hundred small eggs daily and eggs hatch within about 1 day 
- low adult densities suggest poor juvenile survival.

Pegasids are likely to be extracted from wild populations at increasing rates. As by-products of the food fishery, they will suffer from drives by the PRC and Vietnam (and other nations) to increase fishing yields, particularly in the Gulf of Tonkin. After years of low exploitation because of armed conflict in the area, the Gulf of Tonkin is now the focus of an intensive trawl fishery, with greatly increased numbers of more powerful boats. Officials in China and Vietnam are urging greater yields of food fishes each year, despite evidence that stocks of many fishes in the region are already declining markedly (Luo Ji-Zhang, pers. comm.). Pegasids are among the vulnerable non-target species, here and elsewhere in the Indo-Pacific.

Direct demand for pegasids will probably increase. The current rapid economic growth in China is favouring greater sales of many medicinal animal and plant products; for example, TCM importers in China reported that demand for seahorses - near-relatives to pegasids - is increasing by $8-10$ per cent per year, with one TCM importer claiming a tenfold increase in sales in 10 years (Vincent, 1995, 1996). Pegasids are commonly used as a cheap alternative to seahorses or pipefishes in treating the same maladies. As the latter become ever more difficult to obtain (Vincent, 1995, 1996), we may see a shift to pegasids, with a consequent increase in demand. The increasing prices for seahorses in some regions (Vincent, 1996) could also potentially enhance demand for pegasids.

There is already some evidence of geographic expansion in the trade outside the Gulf of Tonkin region, apart from the aborted attempt at pegasid trading in the central Philippines. In 1995, the author found no awareness of market value for pegasids in Vietnam or Indonesia. However, by 1996, dried pegasid sales were reported in southern Vietnam (Kien Giang province) and northwestern Sulawesi in Indonesia (where there had previously been none). Some pegasids also enter the British aquarium trade from Sri Lanka and Kenya (R. Sankey, pers. comm.).
While it is currently impossible to provide a definitive assessment of the conservation status of pegasids, we can be certain of large takes from the Gulf of Tonkin. This should be enough to alert us to a potential problem and to encourage further monitoring; the global nature of the seahorse fishery only became evident after focused investigation (Vincent, 1995, 1996).

The parallels with the seahorse trade are evident. China once obtained most of its seahorses from domestic waters where they, too, were primarily a bycatch of food fishing. Now, perhaps 10 years later, China has virtually no domestic production and traders acknowledge that seahorses have been sufficiently overexploited to depress numbers and sizes dramatically (Vincent, 1996). China must now import large volumes of seahorses to meet increasing demand for their use in TCM. Apparently, as a consequence, seahorse populations in many countries are showing evidence of overfishing (Vincent, 1995, 1996).

Pegasids should certainly be watched as yet another group of vulnerable species. Neither of the pegasid species currently traded for TCM has yet been studied biologically. Nor are there any reports of pegasid culturing. It will be important to respond quickly to hints of declining pegasid numbers. One problem is that by-catches of trawl fisheries - including pegasids-are seldom even monitored, let alone managed.

\section{Acknowledgements}

I am most grateful to the many people who kindly provided information, especially those in China and Hong Kong. I particularly thank Fox Wong, my research assistant and interpreter in China, and Paul But of the Chinese University of Hong Kong for his help in researching their medical uses. Marivic Pajaro collected the Philippines information as part of an ongoing study into pegasids funded by Fauna \& Flora International through its 100\% Fund. I thank Sara Lourie for help with figures. This research into pegasid trade was further facilitated by support for related seahorse studies from National Geographic, Darwin Initiative for the Survival of Species (UK Department of the Environment), Whitley Award (Royal Geographical Society and the Whitley Animal Preservation Trust) and British 
Airways Assisting Conservation. WWF Hong Kong, TRAFFIC East Asia, and the Swire Institute of Marine Sciences (University of Hong Kong) provided logistic and other support, for which I thank them.

\section{References}

Babu, S.J. 1966. Occurrence of the bat-fish, Pegasus volitans (Pegasiformes; Pegasidae), from the coastal waters of India. J. Bombay Nat. Hist. Soc. 63, 210-211.

Günther, A.C.L.G. 1870. Catalogue of Fishes in the British Museum. Trustees of the Brit. Mus., London, Vol. 8. xxv + 549 pp.

Herold, D. and Clark, E. 1993. Monogamy, spawning and skin-shedding of the sea moth, Eurypegasus draconis (Pisces: Pegasidae). Env. Biol. Fish. 37, 219-236.

Jiangsu New Medical College. 1977. Encyclopaedia of Chinese Materia Medica. Shanghai Science and Technology Press, Shanghai.

Kuiter, R. 1985. The remarkable seamoth. Scuba Diver, 3, 16-18.

Li Pei and Lin Jian Ye. 1992. Curing Disease by Eating Seafood. Nanjing University Press, Nanjing, PRC.

Palsson, W.A. and Pietsch, T.W. 1989. Revision of the acanthopterygian fish family Pegasidae (order Gasterosteiformes). Indo-Pacific Fishes, 18, 1-38.

Pietsch, T.W. 1978. Evolutionary relationships of the sea moths (Teleostei: Pegasidae) with a classification of gasterosteiform families. Copeia, 1978, 517-529.

Tang, W.-C. 1987. Chinese medicinal materials from. the sea. Abstracts in Chinese Medicine, 1, 571-600.

Vincent, A.C.J. 1995. Trade in seahorses for Traditional Chinese Medicines, aquarium fishes and curios. TRAFFIC Bulletin, 15, 125-128.

Vincent, A.C.J. 1996. The International Trade in Seahorses. TRAFFIC International, Cambridge, UK.

Wan, D.K. and Wu, J.R. 1993. Medical Zoology. Shanghai Science and Technology Press, Shanghai.

Zhongguo Yaoyong Dongwu Zhi. Medicinal Fauna in China Committee. 1983. Medicinal Fauna of China 2. Tianjin Science and Technology Press, PRC.

Amanda Vincent, Department of Zoology, University of Oxford, South Parks Road, Oxford OX1 3PS, UK. Current address: Department of Biology, McGill University, 1205 Ave. Dr. Penfield, Montréal, Québec H3A 1B1 Canada. 